\title{
ARTICLE
}

WWw.gmj.ir

Received 2020-12-07

Revised 2021-02-22

Accepted 2021-05-28

\section{Contradictory Effect of Notch1 and Notch2 on Phosphatase and Tensin Homolog and its Influence on Glioblastoma Angiogenesis}

\author{
Mostafa Shabani1 ${ }^{1,2}$, Hamid Taghvaei Javanshir ${ }^{1,2}$, Ahmad Bereimipour ${ }^{2,3}$, Amin Ebrahimi Sadrabadi², Arsalan Jalili², \\ Karim Nayernia 4 四 \\ Medical Genomics Research Center, Tehran Medical Sciences Islamic Azad University, Tehran, Iran \\ ${ }^{2}$ Department of Stem Cells and Developmental Biology, Cell Science Research Center, Royan Institute for Stem Cell Biology and \\ Technology, ACECR, Tehran, Iran \\ ${ }^{3}$ Young Researchers and Elite Club, Tehran Medical Sciences Islamic Azad University, Tehran, Iran \\ ${ }^{4}$ International Center for Personalized Medicine, Düsseldorf, Germany
}

\begin{abstract}
Many genes induce angiogenesis in tumors, and among them, Notch family genes have received particular attention due to their extensive network of connections with other genes active in this function. Suppression of angiogenic signaling has been studied in various cancers, confirming Notch's fundamental and extensive role. According to studies, four Notch genes work independently with many genes such as vascular endothelial growth factor, phosphatase and tensin homolog, Phosphoinositide 3-kinase/Akt, and matrix metalloproteinases, and so many other genes, as well as proteins (such as hypoxia-inducible factor-1 alpha) significantly affect tumor angiogenesis. Notchl regular activity in a healthy person causes angiogenesis in body tissues, controlled by normal Notch 2 activity. However, in many cases of glioblastoma, whether on patients or tumor xenografts or in vivo models, a mutation in one of these two essential genes or at least one of the genes and proteins that affected by them can cause better angiogenesis in hypoxic conditions and lead to become an invasive tumor. In this review, we examined the contrasting activity of Notch 1 and Notch 2 and the signaling cascade that each generates in the angiogenesis of glioblastoma, the most invasive cancer of the central nervous system.
\end{abstract}

[GMJ.2021;10:e2091] DOI:10.31661/gmi.v10i0.2091

Keywords: Glioblastoma; Angiogenesis; Notch1; Notch2

\section{Introduction}

$\mathrm{G}$ lioma is the most malignant type of J primary brain tumor that is highly resistant to chemotherapy and other medications. According to the World Health Organization (WHO) classification, glioma with rapid cell proliferation and high resistance to treatment and optimized angiogenesis consist of four histopathological degrees (I-IV), including pilocytic astrocytomas, diffuse astrocytomas,

\section{GMJ}

Copyright $($ 2021, Galen Medical Journal. This is an open-access article distributed under the terms of the Creative Commons Attribution 4.0 International License (http://creativecommons.org/licenses/by/4.0/) Email:info@gmj.ir anaplastic astrocytomas, and type IV glioma astrocytoma or glioblastoma multiform (GBM) [1]. Astrocytes are the most abundant type of glial cells in the brain that are multifunctional cells with different central nervous system (CNS) roles and can cause several diseases. They also can control nerve synapses, regulate homeostasis, supply energy to neurons, and recycle neurotransmitters [2-4]. GBM accounts for about $70 \%$ of all gliomas [5].

\footnotetext{
Correspondence to:

Karim Nayernia, International Center for Personalized Medicine, Düsseldorf, Germany.

Telephone Number: +4921144773490

Email Address: info@icpm.center
} 
The current standard of care for patients with GBM includes surgical intervention with maximum possible tumor resection, followed by concomitant radiotherapy (RT) and chemotherapy with temozolomide (TMZ) and then the adjunctive drug TMZ, which is an oral alkylating agent; due to its small size, it is easily absorbed in the intestine and passes through the blood-brain barrier [6,7]. Despite these invasive treatments, patients' maximum survival time is estimated at 14.6 months, with a mortality rate of nearly a hundred percent $[8,9]$. Tumor angiogenesis is regulated by a complex network of signaling pathways, including vascular endothelial growth factor (VEGF), epidermal growth factor receptor (EGFR), peritumoral brain edema (PTBE), P53, and Notch. Although not all of the mechanisms involved are known, the Notch signaling pathway is critical in tumor angiogenesis [1]. Notch signaling plays an important role in regulating many stem cell processes such as proliferation, stem cell maintenance, differentiation during embryonic and adult development, homeostasis of adult regenerative organs, and CNS development $[10,11]$. In mammals, Notch consists of four hetero-oligomer single-pass types I transmembrane receptors (Notch 1-4) and five ligands from the Delta-Serrate-Lag family, including Jagged1 (JAG1) and JAG2, delta-like 1 (DLL1), DLL3, and DLL4 belong to the Serrate family of ligands. Notch receptors are heterodimers with extra- and intracellular functional domains that mediate the target gene's transcription [1]. According to reviewed information and the Notch signaling pathway's crucial and contradictory function in inhibiting or inducing angiogenesis, this study aims to determine Notch 1 and Notch 2 in the signaling current that each creates and finally finds a suitable solution to inhibit angiogenesis in GBM or suggest reliable treatment.

\section{Notch Signaling Expression Pattern in GBM}

The Notch signaling pathway is disrupted in three-quarters of human GBM, and its growth is suppressed explicitly by inhibiting a receptor in the Notch family [12-14]. Notch1, Notch4, DLL1, DLL2, JAG1,
Centromere-binding protein-1 (CBF1), Hairy/enhancer-of-split related with YRPW motif protein-1 (HEY1), HEY2, and hairy and enhancer of split-1 (HES1) mRNA and protein levels are higher in brain tumor cells than in normal brain tissue, and also with increased VEGF and Phosphorylated protein kinase, strain AK, Thymoma ( $p A K T$ ) expressions, and decreased Phosphatase and tensin homolog (PTEN) levels [15-17]. For example, higher expression of AchaeteScute Family BHLH Transcription Factor-1 (ASCL1), DLL1, Notch1, Notch3, Notch4, and Heyl is associated with high-grade glioma and a worse prognosis $[18,19]$. As a result, the more active Notch signaling, the more differentiated and aggressive the tumor phenotype. Some research also suggests that Notch activation creates a specific cellular fate, especially distinguishing certain glia types, such as radial glia and astrocytes $[20,21]$.

\subsection{Notch1 Signaling Overview}

According to studies, among the four Notch genes active in GBM angiogenesis, Notchl plays the most crucial role. It works in low oxygen conditions concentration with the participation of Hypoxia Inducible Factor (HIF-1 $\alpha$ ). Suppression of Notchl impairs the proliferation and survival of glioma cell lines as well as human gliomas. Notchl expression is higher in patients with a chance of survival of more than one year than in less than one year of age. However, Notchl overexpression is less associated with overall survival (OS), suggesting a controversial role for Notch1 in GBM [22,23]. Microglia/macrophages enhance glioma growth by secreting proteolytic enzymes and several angiogenic factors such as matrix metalloproteinases (MMPs), $V E G F$, and affecting nuclear factor kappa $\mathrm{B}$

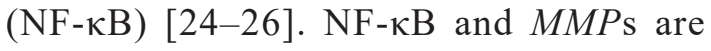
involved in tumor cell invasion and tumor angiogenesis, inactivated by Notchl inhibition [27]. Besides, the limiting effect of Notch1 on PTEN signaling has been observed [28].

\subsection{Notch2 Signaling Overview}

Notch2 is known to be a significant prognostic marker in glioma independent of other mutation patterns [29]. The level of Notch2 
expression in GBM is associated with stem genes (nestin and SRY-Box Transcription Factor-2), fate genes (expected outcome of normal development), astrocytes (vimentin and Glial Fibrillary Acidic Protein), and anti-apoptotic proteins (BCL6 and BCL-W) but is inversely related to Oligodendrocyte Transcription Factor-2 (Olig2), C-type natriuretic peptide (CNP), and PLP1 (oligodendrocyte fate) and proapoptotic proteins (apoptosis promoters) such as Bcl-2-associated X protein and Bcl-2-associated transcription factor 1 [30,31]. Positive regulation of Notch2 expression effectively suppresses cell growth and invasion and induces apoptosis [1]. In a study of the malignant mesothelioma, an invasive tumor of the pleura, pericardium, and peritoneum, Notch 2 negatively regulated PI3k-Akt and found that Notch2 could activate PTEN, both of which inhibition of angiogenesis plays a pivotal role [28]. Another study showed that negative Notch 2 regulation induced by siRNA in gastric cancer cells increases the invasive function of tumor cells, enhances the expression and activity of $M M P$ 9, and increases the phosphorylation of the PI3K pathway, as with growing p-Akt was shown [32].

\subsection{Notch3 Signaling Overview}

Notch3 is a prognostic factor expressed in the CNS, vascular smooth muscle, and some hematopoietic cells; and enhances cell proliferation, migration, and invasion, which inactivates cell apoptosis [1,33]. Activation of Notch 3 causes invasive glioma formation in the optic nerve but has no confirmed effect on GBM. It has also been observed that Notch 3 increases expression in hypoxic conditions and contributes to significant angiogenesis [34-39]. Some studies suggest Notch3 has an impact on EGFR gene expression, which could potentiate PI3K function. Also, research shows that Notch3 plays an essential role in fibroblast-dependent angiogenesis $[40,41]$.

\subsection{Notch4 Signaling Overview}

High expression of Notchl indicates higher differentiation, while increased expression of Notch 4 may indicate a lower degree of differentiation and possibly a tumor with more aggressive function [30]. Not much is known about the cooperation of Notch4 with other genes affecting glioma, and more studies are needed. Information obtained by Uyttendaele et al. [42] shows that among the components of the DLL4-Notch pathway, DLL4 and Notch 4 are expressed explicitly in tumor endothelial cells. This important association and specific morphology showed that DLL4Notch4 signaling in endothelial cells plays a vital role in GBM angiogenesis. It has been suggested that Notch1 and Notch4 may have similar functions in angiogenesis, regulating, and acting on them in different combinations in different cell types [42]. In summary, the functional role of Notch1 and Notch2 compared to Notch 3 and Notch4 in influencing GBM is better known, scientifically proven, and has a meaningful place in angiogenesis research and the challenging effect of these two genes. Also, their signaling pathway has been studied in various cancers. Numerous articles have examined the promoting or limiting impact of Notch1 and Notch2 on cell lines, tumor xenografts, animal models, and human tumor specimens.

\section{Notch Signaling and Angiogenesis}

Blood vessel formation is a dynamic and complicated process that plays a crucial role in health state and disease vulnerability. Delicate balance-dependent angiogenesis is regulated between anti-angiogenic and pro-angiogenic molecules and angiogenesis in tumors. Angiogenesis occurs when pro-angiogenic stimuli are more potent $[43,44]$. Among the many signaling pathways that affect angiogenesis, the Notch signaling pathway is a ligand-receptor cascade that plays a vital role in guiding cellular fate and vascular development and inducing tumor angiogenesis $[45,46]$. Two key ligands mediate Notch paracrine receptors in glioma stem cells (GSCs), $D L L 4$, and $J A G 1$, expressed in epithelial cells (ECs) [47].

\subsection{DLL4}

DLL4 is a Notch1 ligand that plays a vital role in vascular development and is present in active angiogenesis sites. Predictors of tumor progression and survival are indepen- 
dent of age, sex, WHO grade, PTBE, and expression levels of Ki-67, MGMT, and p53 [48-52]. Li, Z. et al. showed that in different ECs classes, hypoxic conditions lead to induction of DLL4 by HIF-1 $\alpha$ [50]. DLL4 levels in tumors and vascular tissue are considered as predictive markers [53]. DLL4-Notch signaling pathway interacts with several molecules and other signaling pathways, including PI3k, EGFR, and $M M P 9$, all related to tumor invasion, proliferation, and metastasis. Notchl-dependent activity in the PI3k-Akt pathway via DLL4 leads to cell migration and invasive cancer $[17,54,55]$.

According to previous observations, overexpression of DLL4 in glioma connective tissue reduces vascular density, improves vascular collapse, reduces intra-tumor hypoxia and necrosis, and ultimately prevents tumor growth. In contrast, inactivating DLL4 causes unproductive angiogenesis (production of a dysfunctional vessels network) with necrosis and hypoxia. DLL4-Notch signaling activity in tumors enhances blood vessels' better perfusion (productive vessels), stimulating tumor growth despite the reduced vascular density and improving function within a tumor [56,57]. Besides, the Notch pathway also regulates tumor cell differentiation into ECs in several ways $[14,58,59]$.

\subsection{JAG1}

The Notch /JAG1 signaling pathway can work directly with other essential pathways such as $M M P 9$ and $V E G F$ to regulate glioma growth and malignancy, which defines patients' physical condition with glioma [60]. Numerous articles indicate the $J A G 1$ signaling pathway as a modulator of angiogenesis associated with $D L L 4$, with $J A G 1$ somewhat limiting $D L L 4$ function to keep it out of control. In other words, JAG1 and DLL4, as Notch1 ligands, together cause normal angiogenesis, and any dysfunction of either causes inefficient angiogenesis and invasive tumor [61].

\subsection{HES1}

HES1 is a transcription factor and downstream target in the Notch1 signaling pathway. According to studies, it is located on human arterial ECs, and its significant effect on the regulation and morphologic changes of angiogenesis is confirmed [62]. Tumor growth factor- $\alpha$ (TGF- $\alpha$ ) can also regulate HES1 expression independently of Notch1 function and introduce HES1 nuclear import in the presence of ERK1/2 activation. They synergistically promote the growth of glioma cells [63]. One of the critical tasks of HES1, which has been mentioned in various studies, is to cooperate in the development of tumor angiogenesis under the control of Notch1 and inhibit PTEN function [64-67]. The importance of DLL4 and JAG1 in their complementary function is that the expression of DLL4 in GBM is limited to endothelial cells. It is significantly more common and severe than JAG1; DLL4/Notch angiogenesis's high activity exacerbates GBM. HES1 transcription factor's role as Notchl operating lever in the control and inhibition of PTEN was investigated in many studies.

\section{Factors That Affect Notch Performance}

Many molecular components are involved in and affect the Notch signaling pathway, the most important of which is hypoxia, affecting Notch $1 / 2$ performances through the HIF- $1 \alpha$ induction factor. This effect can be inhibitory or inductive.

Another important pathway leading to angiogenesis regulated by Notch $1 / 2$ and having significant hypoxia activity is $P I 3 k-A k t-M M P 9$, which is inhibited by the PTEN removed on chromosome 10 [68-72]

\subsection{Hypoxia Regulate Angiogenesis in GBM} Tumor angiogenesis is essential for tumor growth and progression, and solid tumors often have increased hypoxia, a potent angiogenesis stimulus. Low oxygen levels may be due to structural abnormalities in the tumor vessels or the tumor size, leading to inadequate oxygen delivery. Changes in gene expression may help the tumor adapt to its hypoxic environment. One of the induced genes is HIF1. HIF1 is a heterodimeric protein belonging to the basic helix-loop-helix family of transcription factors. It regulates the expression of many genes involved in tumor progressions, such as VEGF and Notch [73]. Before the induction of angiogenesis, 
cells survive in the tumor mass inside and away from blood vessels in nutrient deficiency conditions and inadequate oxygen supply. The association between hypoxic conditions and the Notch pathway in GMB has been reported in several studies [68-72,74,75]. Under hypoxic conditions, the presence of HIF-1 $\alpha$ increases the stability of the Notch protein and the physical interaction between the two proteins [68]. Hypoxia is one of the hallmarks of GBM, and Notch signaling works best with hypoxia. Five hypoxia markers (HIF-1 $\alpha / \mathrm{PGK} 1 / V E G F / \mathrm{CA} 9 / \mathrm{OPN}$ ) have been identified as the best predictors of Notch1, DLL1, HES1, HES6, HEY1, and HEY2 induction. Also, under hypoxia, GSCs express several Notch-related genes (Notchl, Notch3, DLL1, JAG1, JAG2, HES1, HEY1, HEY2) and hypoxia-related genes (HIF-la, $V E G F, L O X$, and HIG2) increases [69-71]. HIF-1 $\alpha$ induces Notch pathway activity and makes GSCs more sensitive to maintenance in hypoxic conditions. Hypoxic conditions by activating Notch signaling lead glioblastoma cells to increase colony formation, increase cancer stem cell markers' expression, increase neurosphere production, and malignancy. Various mechanisms are involved in the proper formation of blood vessels observed in these tumors. The germination of capillaries caused by existing blood vessels through endothelial proliferation depends on hypoxia at the tumor center [72]. Hypoxia induction factor, which enhances transcription of $V E G F$, is activated in GBM. Hypoxic tumor cells, especially cell around the necrotic nucleus, release vascular growth factors such as $V E G F$, which stimulates the formation of new blood vessels from existing normal endothelial cells [72]. The researchers also explained that Notch activation due to hypoxia could be reversed through targeted Notch therapy. Contrary to the role of HIF-1 $\alpha$ in Notch signaling, the reaction of HIF- $2 \alpha$ and Notch intracellular domain suppresses Notch signaling. HIF- $1 \alpha$ and HIF- $2 \alpha$ bind competitively to the Notch intracellular domain and dynamically regulate Notch signaling activation in GSCs depending on different oxygen stresses (concentration changes), and improved treatment opportunities provide oxygen for various strains $[74,75]$.

\subsection{Over Expression of PI3k-Akt Signaling} Cause Angiogenesis

One of the Notch1 angiogenesis mechanisms is the induction of PI3k-Akt pathway activity via $D L L 4$. PI3k/Akt signaling regulates angiogenesis by affecting expressions of $V E G F$, HIF- $1 \alpha$, and MMP9 [57,76-79].

Activation of PI3k by Notch1 also stimulates the signaling pathways of $M M P 9, \beta$-catenin, and NF- $\kappa \mathrm{B}$, which increases the migratory, invasiveness, and angiogenic properties of glioma cells $[17,77,78]$. Inhibition of the PI3K pathway not only limits tumor cell growth but also inhibits tumor angiogenesis. Interestingly, the PI3K pathway plays an influential role in regulating $V E G F$ and $V E G F R$ [80]. Fibroblast growth factor receptor (FGFR) modulates several tumor cell processes, including FGF-mediated migration and proliferation. FGFR plays a substantial role in the survival and angiogenesis of glioblastoma cells via the $\mathrm{PI} 3 \mathrm{k} / \mathrm{AKT} / \mathrm{mTOR}$ signaling pathway [81].

\subsection{MMP9 Effects On Angiogenesis}

$M M P 9$ is a family of related enzymes that destroy the extracellular matrix and are essential factors in facilitating tumor invasion and metastasis [82-84]. $M M P 9$ is a downstream target for the PI3k/Akt pathway that is crucial in cell proliferation control $[77,78]$. Under physiological conditions, $M M P 9$ plays a vital role in tissue repair in connection with various physiological and pathological processes such as morphogenesis, angiogenesis, tissue repair, cirrhosis, osteoarthritis, and metastasis [85,86]. $M M P 9$ is required to maintain normal/healthy tissue structure and epithelial integrity. Abnormal expression and activity of MMP9 have been reported in pathological conditions, especially in various cancers [85-90].

\subsection{PTEN Controls PI3K/AKT Activation}

$P T E N$ is a tumor suppressor that neutralizes the PI3K/Akt/mTOR pathway with its lipid phosphatase function. Mutation and methylation of PTEN have been detected in at least $60 \%$ of GBM [91]. PTEN may contribute to gliomagenesis and survival by impairing proliferation, migration, invasion, angiogenesis, stem cell self-renewal, and regulation of other tumor suppressor pathways such as P53, 
poorly associated with glioblastoma [91-95]. It has been observed that Notch1 and Notch 2 have different effects on PI3k-Akt signaling with opposed regulation of $P T E N$, which was confirmed by protein and mRNA level analysis. PTEN activity can also have a limiting impact on HIF $1-\alpha$ and $V E G F$. Moreover, thereby inhibiting angiogenesis and tumor survival $[28,79]$. Specifically, in GBM, PTEN loss leads to the expression of VEGFR2 in tumor cells, which may play a role in resistance to angiogenesis inhibitory therapies. A new study also showed that overexpression of VEGFR2 in tumor cells could induce early GBM resistance to TMZ chemotherapy and anti-angiogenic therapy with bevacizumab [96]. Taken together, it seems that Notch1 and its signaling pathways such as PI3k-Akt and $M M P 9$ play a significant role in tumor angiogenesis with the help of VEGF and HIF1- $\alpha$ factors; admittedly, the presence of hypoxia plays a significant role in exacerbating an- giogenesis, and in normoxia, less pro-angiogenic factors will be present. Unlike Notch1, Notch 2 has a more substantial role in tumor growth and plays a suppressive role in tumor angiogenesis through PTEN induction and AKT dephosphorylation [28]. Defects in the expression or function of PTEN are also indirectly associated with anti-angiogenic drug resistance [96].

\section{Influence Inhibition of Notch1 and Notch2 -Induced Expression On Angiogenesis}

Due to Notch 1 and Notch2 proteins' contradictory function in GBM angiogenesis, regulating their activity and downstream signaling for therapeutic methods has been investigated in many articles. In a single-gene therapy study and multi-gene combinatorial therapy on EGFR, PI3K, AKT, and PTEN in GBM, Han et al. reported that $P T E N$ was upregulated by adenoviral-mediated PTEN (Ad-PTEN),
A

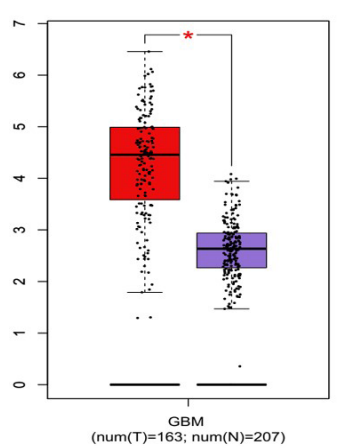

C

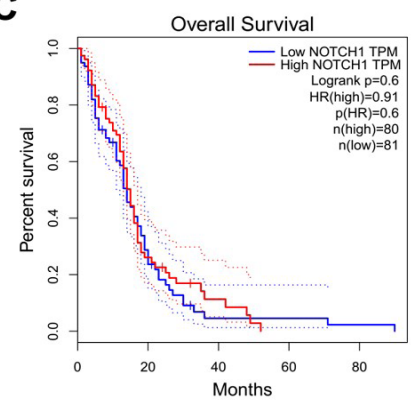

B
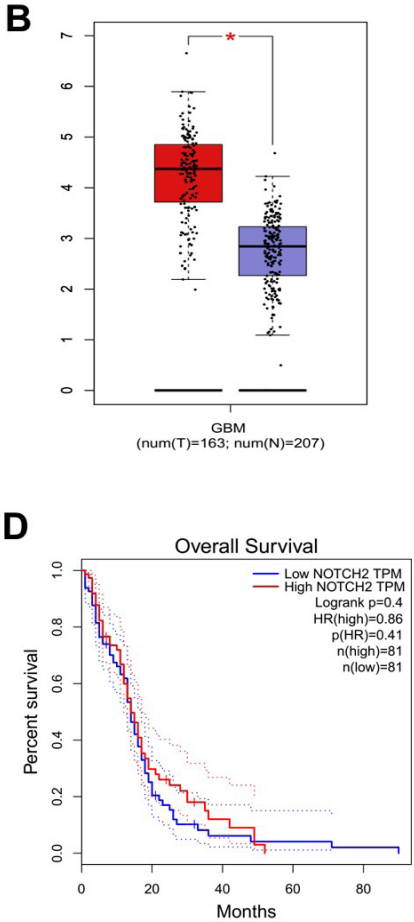

\section{E}

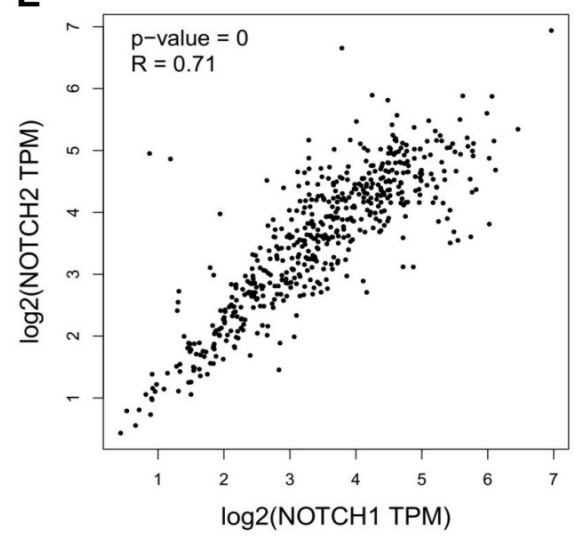

Figure 1. Evaluation of expression, survival, and correlation between Notch1 and Notch2 in GBM. A and B: The expression level of Notch1 and Notch2 is shown as a box plot with a significantly higher expression rate in patients with GBM than healthy people. C and D: The survival chart between these two genes is about 45 months; the survival rate in patients with high expression of these genes is close to zero. E: Correlation between two genes has been shown that with increasing expression of each gene, the other gene has also increased expression. It can be said that these two genes are related to each other. The diagrams were drawn using the GEPIA database. 


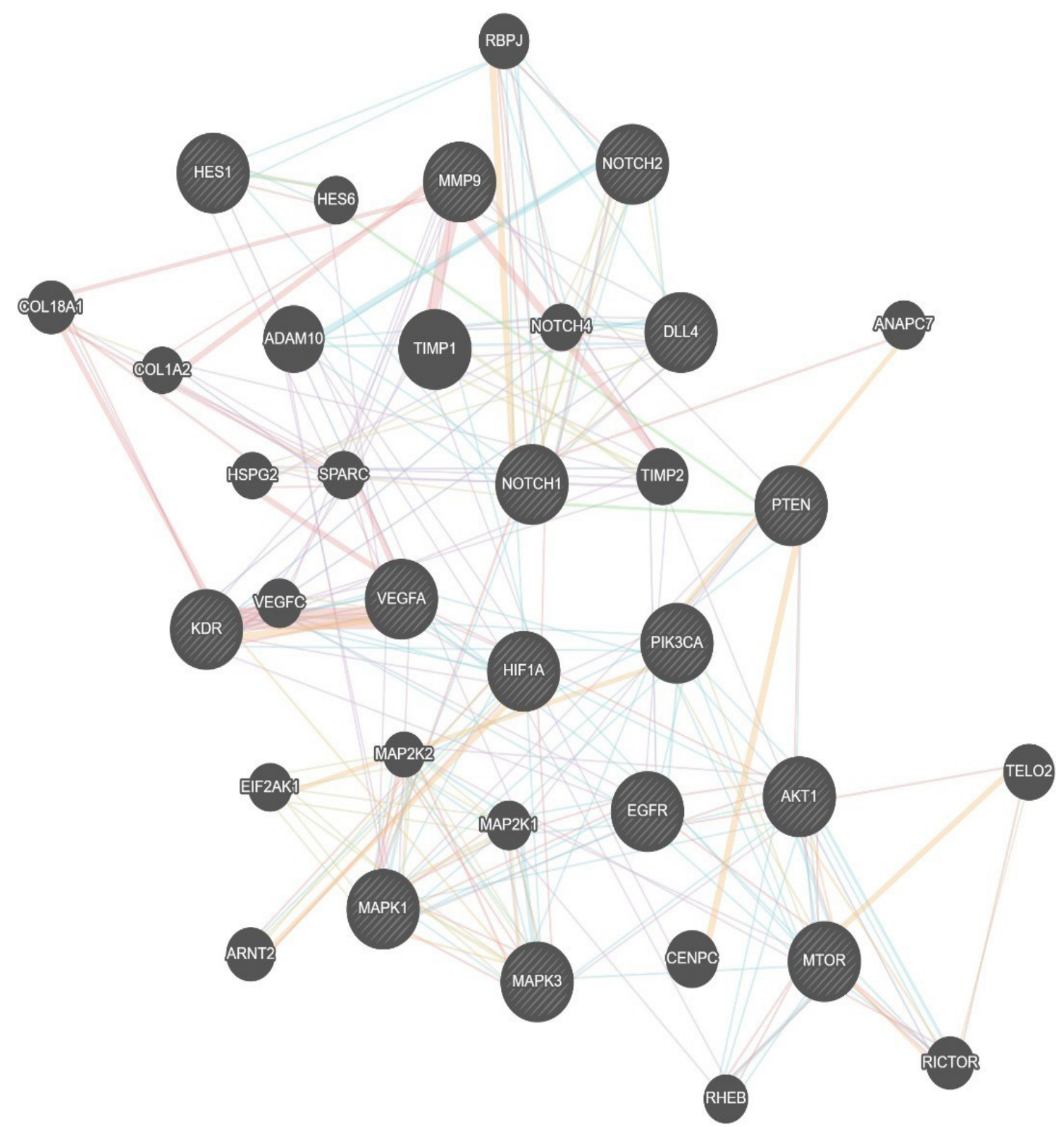

Figure 2. The network drawn using the GeneMANIA database shows the relationship between the upstream and downstream genes Notch1 and Notch2. The circles and the connections between the lines of each gene show the importance of that gene in the network.

and PI3K was suppressed by LY294002 (Figure-1, Figure-2) $[95,97,98]$. The effect of this combination therapy was evaluated on glioma cell lines (U251 and LN229) and tumor xenograft (U251). Although multi-gene combination therapy is far more effective than selective gene therapy, it still cannot completely inhibit glioma growth, and further studies are suggested $[95,97,98]$.

In another study, researchers used Notch1 siRNA to reduce Notchl function and increase Plasmid-induced Notch2 expression.
Notch1 siRNA transfer to GSCs suppresses the Notch1 gene. Notch1 mRNA level and according to Western blot analysis, Notch1 protein was significantly reduced in this group compared to the control group $[99,100]$.

\section{Conflict of Interest}

The authors declared that they have no conflict of interest. 


\section{References}

1. Yan D, Hao C, Xiao-feng L, Yu-chen L, Yu-bin F, Lei Z. Molecular mechanism of Notch signaling with special emphasis on microRNAs: Implications for glioma. J Cell Physiol. 2018;234:158-70.

2. MolofskyAV,Krencik R, Krenick R, Ullian EM, Ullian E, Tsai $\mathrm{H}$, et al. Astrocytes and disease: a neurodevelopmental perspective. Genes Dev. 2012; 26(9):891907.

3. Parpura V, Heneka MT, Montana V, Oliet SHR, Schousboe A, Haydon PG, et al. Glial cells in physiology. J Neurochem. 2012;121:4-27.

4. Pekny M, Wilhelmsson U, Pekna M. The dual role of astrocyte activation and reactive gliosis. Neurosci Lett. 2014;565:30-8.

5. Louis DN, Perry A, Reifenberger G, von Deimling A, Figarella-Branger D, Cavenee WK, et al. The 2016 World Health Organization Classification of Tumors of the Central Nervous System: a summary. Acta Neuropathol. 2016; 131(6):803-20.

6. Clarke J, Butowski N, Chang S. Recent Advances in Therapy for Glioblastoma. Arch Neurol . 2010;67(3):279-83.

7. Wesolowski JR, Rajdev P, Mukherji SK. Temozolomide (Temodar). AJNR Am J Neuroradiol. 2010;31(8):1383-4.

8. Roy S, Lahiri D, Maji T, Biswas J. Recurrent Glioblastoma: Where we stand. South Asian J Cancer. 2015;4(4):163-73.

9. Wilson $T$, Karajannis $M$, Harter D. Glioblastoma multiforme: State of the art and future therapeutics. Surg Neurol Int . 2014;5:64.

10. Mathieu P, Adami PVM, Morelli L. Notch signaling in the pathologic adult brain. Biomol Concepts. 2013;4(5):465-76.

11. Bray SJ. Notch signalling: a simple pathway becomes complex. Nat Rev Mol Cell Biol. 2006;7(9):678-89.

12. Wang J, Yan Z, Liu X, Che S, Wang C, Yao W. Alpinetin targets glioma stem cells by suppressing Notch pathway. Tumour Biol. 2016;37(7):9243-8.

13. Liau BB, Sievers C, Donohue LK,
Gillespie SM, Flavahan WA, Miller TE, et al. Adaptive Chromatin Remodeling Drives Glioblastoma Stem Cell Plasticity and Drug Tolerance. Cell Stem Cell. 2017;20(2):233-46.e7.

14. Jin Z, Zhan T, Tao J, Xu B, Zheng H, Cheng Y, et al. MicroRNA - 34a induces transdifferentiation of glioma stem cells into vascular endothelial cells by targeting Notch pathway. Biosci Biotechnol Biochem. 2017;81(10):1899-1907.

15. Kanamori M, Kawaguchi T, Nigro JM, Feuerstein BG, Berger MS, Miele L, et al. Contribution of Notch signaling activation to human glioblastoma multiforme. J Neurosurg. 2007;106(3):417-27.

16. Hulleman E, Quarto M, Vernell R, Masserdotti G, Colli E, Kros JM, et al. A role for the transcription factor HEY1 in glioblastoma. J Cell Mol Med. 2008;13(1):136-46.

17. Zhang X, Chen T, Zhang J, Mao Q, Li S, Xiong W, et al. Notch1 promotes glioma cell migration and invasion by stimulating $\beta$-catenin and NF- $\kappa \mathrm{B}$ signaling via AKT activation. Cancer Sci. 2012;103(2):18190.

18. Phillips HS, Kharbanda S, Chen R, Forrest WF, Soriano RH, Wu TD, et al. Molecular subclasses of high-grade glioma predict prognosis, delineate a pattern of disease progression, and resemble stages in neurogenesis. Cancer Cell. 2006;9(3):15773.

19. Somasundaram K, Reddy SP, Vinnakota K, Britto R, Subbarayan M, Nambiar S, et al. Upregulation of ASCL1 and inhibition of Notch signaling pathway characterize progressive astrocytoma. Oncogene. 2005;24(47):7073-83.

20. Nye JS, Kopan R, Axel R. An activated Notch suppresses neurogenesis and myogenesis but not gliogenesis in mammalian cells. Development. 1994;120(9):2421-30.

21. Morrison SJ, Perez SE, Qiao Z, Verdi JM, Hicks C, Weinmaster G, et al. Transient Notch activation initiates an irreversible switch from neurogenesis to 
gliogenesis by neural crest stem cells . 2000;101(5):499-510.

22. Xing Z, Sun L, Guo W. Elevated expression of Notch-1 and EGFR induced apoptosis in glioblastoma multiforme patients. Clin Neurol Neurosurg . 2015;131:54-8.

23. Han N, Hu G, Shi L, Long G, Yang L, Xi Q, Guo Q, Wang J, Dong Z, Zhang M. Notch1 ablation radiosensitizes glioblastoma cells. Oncotarget. 2017;8(50):88059-68.

24. Demuth T, Berens ME. Molecular Mechanisms of Glioma Cell Migration and Invasion. J Neurooncol. 2004;70(2):21728.

25. Zhai H, Heppner FL, Tsirka SE. Microglia/macrophages promote glioma progression. Glia . 2011;59(3):472-85.

26. Alterman RL, Stanley ER. Colony stimulating factor-1 expression in human glioma. Mol Chem Neuropathol. 1994;21(2-3):177-88.

27. Wang Z, Li Y, Banerjee S, Kong D, Ahmad A, Nogueira V, Hay N, Sarkar FH. Down-regulation of Notch-1 and Jagged-1 inhibits prostate cancer cell growth, migration and invasion, and induces apoptosis via inactivation of Akt, mTOR, and NF-kappaB signaling pathways. J Cell Biochem. 2010;109(4):726-36.

28. Graziani I, Eliasz S, De Marco MA, Chen Y, Pass HI, De May RM, et al. Opposite effects of Notch-1 and Notch-2 on mesothelioma cell survival under hypoxia are exerted through the Akt pathway. Cancer Res. 2008;68(23):9678-85.

29. Yu HP, Qi ST, Feng WF, Zhang GZ, Zhang HP, Tian JJ. Interference of Notch 2 inhibits the progression of gliomas and induces cell apoptosis by induction of the cell cycle at the G0/G1 phase. Mol Med Rep. 2015;11(1):734-8.

30. Dell'Albani P, Rodolico M, Pellitteri R, Tricarichi E, Torrisi SA, D'Antoni S, et al. Differential patterns of NOTCH1-4 receptor expression are markers of glioma cell differentiation. Neuro Oncol. 2014;16(2):204-16.

31. Tchorz JS, Tome M, Cloëtta D, Sivasankaran B, Grzmil M, Huber RM, et al. Constitutive Notch2 signaling in neural stem cells promotes tumorigenic features and astroglial lineage entry. Cell Death
Dis. 2012;3(6):e325.

32. Guo L-Y. Notch2 regulates matrix metallopeptidase 9 via $\mathrm{PI} 3 \mathrm{~K} / \mathrm{AKT}$ signaling in human gastric carcinoma cell MKN-45. World J Gastroenterol. 2012;18(48):7262-70.

33. Hofmann JJ, Iruela-Arispe ML. Notch signaling in blood vessels: who is talking to whom about what?. Circ Res. 2007;100(11):1556-68.

34. Liu H, Zhang W, Kennard S, Caldwell RB, Lilly B. Notch3 Is Critical for Proper Angiogenesis and Mural Cell Investment. Circ Res. 2010;107(7):860-70.

35. Villa N, Walker L, Lindsell CE, Gasson $\mathrm{J}$, Iruela-Arispe ML, Weinmaster G. Vascular expression of Notch pathway receptors and ligands is restricted to arterial vessels. Mech Dev. 2001;108(12):161-4.

36. Loomes KM, Taichman DB, Glover CL, Williams PT, Markowitz JE, Piccoli DA, et al. Characterization of Notch receptor expression in the developing mammalian heart and liver. Am J Med Genet. 2002;112(2):181-9.

37. Lindsell CE, Boulter J, diSibio G, Gossler A, Weinmaster G. Expression Patterns ofJagged, Delta1, Notch1, Notch2, andNotch3Genes Identify Ligand-Receptor Pairs That May Function in Neural Development. Mol Cell Neurosci. 1996;8(1):14-27.

38. Joutel A, Andreux F, Gaulis S, Domenga $\mathrm{V}$, Cecillon M, Battail N, et al. The ectodomain of the Notch3 receptor accumulates within the cerebrovasculature of CADASIL patients. J Clin Invest. 2000;105(5):597-605.

39. Wang T, Baron M, Trump D. An overview of Notch3 function in vascular smooth muscle cells. Prog Biophys Mol Biol. 2008;96(1-3):499-509.

40. Alqudah MAY, Agarwal S, Al-Keilani MS, Sibenaller ZA, Ryken TC, Assem M. NOTCH3 Is a Prognostic Factor That Promotes Glioma Cell Proliferation, Migration and Invasion via Activation of CCND1 and EGFR. PLoS One. 2013;8(10):e77299.

41. Liu H, Kennard S, Lilly B. NOTCH3 Expression Is Induced in Mural Cells 
Through an Autoregulatory Loop That Requires Endothelial-Expressed JAGGED1. Circ Res. 2009;104(4):46675.

42. Uyttendaele H, Marazzi G, Wu G, Yan Q, Sassoon D, Kitajewski J. Notch4/ int-3, a mammary proto-oncogene, is an endothelial cell-specific mammalian Notch gene. Development. 1996;122(7):2251-9.

43. Bolós V, Grego-Bessa J, de la Pompa JL. Notch Signaling in Development and Cancer. Endocr Rev. 2007;28(3):339-63.

44. Artavanis-Tsakonas S, Rand MD, Lake RJ. Notch Signaling: Cell Fate Control and Signal Integration in Development. Science. 1999;284(5415):770-6.

45. Hanahan D, Folkman J. Patterns and Emerging Mechanisms of the Angiogenic Switch during Tumorigenesis. Cell. 1996;86(3):353-64.

46. Bergers G, Benjamin LE. Tumorigenesis and the angiogenic switch. Nat Rev Cancer. 2003;3(6):401-10.

47. Sharma A, Shiras A. Cancer stem cellvascular endothelial cell interactions in glioblastoma. Biochem Biophys Res Commun. 2016;473(3):688-92.

48. Williams CK, Segarra M, De La Luz Sierra M, Sainson RCA, Tosato G, Harris AL. Regulation of CXCR4 by the Notch Ligand Delta-like 4 in Endothelial Cells. Cancer Res. 2008;68(6):1889-95.

49. El Hindy N, Keyvani K, Pagenstecher A, Dammann P, Sandalcioglu IE, Sure U, et al. Implications of Dll4Notch signaling activation in primary glioblastoma multiforme. Neuro Oncol. 2013;15(10):1366-78.

50. Li Z, Wang J, Gong L, Wen Z, Xu C, Huang $X$. Correlation of Delta-like ligand 4 (DLL4) with VEGF and HIF-1 $\alpha$ expression in human glioma. Asian Pac J Cancer Prev. 2011;12(1):215-8.

51. Qiu X, Chen L, Wang C, Lin Z, Zhou C, Liu S, et al. High Delta-Like Ligand 4 (DLL4) Is Correlated With Peritumoral Brain Edema and Predicts Poor Prognosis in Primary Glioblastoma. Medicine (Baltimore). 2014;93(8):e57.

52. Qiu X, Wang C, Lin Z, You N, Wang X, Chen $Y$, et al. Correlation of high deltalike ligand 4 expression with peritumoral brain edema and its prediction of poor prognosis in patients with primary high-grade gliomas. J Neurosurg. 2015;123(6):1578-85.

53. Li J-L, Sainson RCA, Oon CE, Turley H, Leek R, Sheldon H, et al. DLL4-Notch Signaling Mediates Tumor Resistance to Anti-VEGF Therapy In Vivo. Cancer Res. 2011;71(18):6073-83.

54. Kenig S, Alonso MBD, Mueller MM, Lah TT. Glioblastoma and endothelial cells cross-talk, mediated by SDF-1, enhances tumour invasion and endothelial proliferation by increasing expression of cathepsins B, S, and MMP-9. Cancer Lett. 2010;289(1):53-61

55. Cheng L, Huang Z, Zhou W, Wu Q, Donnola S, Liu JK, et al. Glioblastoma Stem Cells Generate Vascular Pericytes to Support Vessel Function and Tumor Growth. Cell. 2013;153(1):139-52.

56. Ridgway J, Zhang G, Wu Y, Stawicki S, Liang W-C, Chanthery Y, et al. Inhibition of D114 signalling inhibits tumour growth by deregulating angiogenesis. Nature. 2006;444(7122):1083-7.

57. Noguera-Troise I, Daly C, Papadopoulos NJ, Coetzee S, Boland P, Gale NW, et al. Blockade of Dll4 inhibits tumour growth by promoting non-productive angiogenesis. Nature. 2006; 444(7122):1032-7.

58. Lobov IB, Renard RA, Papadopoulos N, Gale NW, Thurston G, Yancopoulos GD, et al. Delta-like ligand 4 (D114) is induced by VEGF as a negative regulator of angiogenic sprouting. Proc Natl Acad Sci. 2007;104(9):3219-24.

59. R B, M H. Notch as a hub for signaling in angiogenesis. Exp Cell Res. 2013;319(9):1281-8.

60. Qiu X, Wang C, You N, Chen B, Wang X, Chen $\mathrm{Y}$, et al. High Jagged1 expression is associated with poor outcome in primary glioblastoma. Med Oncol . 2015;32(1):341.

61. Jubb AM, Browning L, Campo L, Turley $\mathrm{H}$, Steers G, Thurston G, et al. Expression of vascular Notch ligands Delta-like 4 and Jagged-1 in glioblastoma. Histopathology. 2012;60(5):740-7.

62. Zhang J, Chen Y, Qiu X, Tang W, Zhang $\mathrm{J}$, Huang $\mathrm{J}$, et al. The vascular delta- 
like ligand-4 (DLL4)-Notch4 signaling correlates with angiogenesis in primary glioblastoma: an immunohistochemical study. Tumor Biol. 2016;37(3):3797-805.

63. Zheng Y, Lin L, Zheng Z. TGF- $\alpha$ induces upregulation and nuclear translocation of Hes1 in glioma cell. Cell Biochem Funct. 2008;26(6):692-700.

64. Palomero T, Lim WK, Odom DT, Sulis ML, Real PJ, Margolin A, et al. NOTCH1 directly regulates c-MYC and activates a feed-forward-loop transcriptional network promoting leukemic cell growth. Proc Natl Acad Sci U S A. 2006;103(48):18261-6.

65. Jarriault S, Brou C, Logeat F, Schroeter EH, Kopan R, Israel A. Signalling downstream of activated mammalian Notch. Nature. 1995;377(6547):355-8.

66. Weng AP, Millholland JM, YashiroOhtani Y, Arcangeli ML, Lau A, Wai C, et al. c-Myc is an important direct target of Notch1 in T-cell acute lymphoblastic leukemia/lymphoma. Genes Dev . 2006;20(15):2096-109.

67. Satoh Y, Matsumura I, Tanaka H, Ezoe S, Sugahara $\mathrm{H}$, Mizuki $\mathrm{M}$, et al. Roles for c-Myc in Self-renewal of Hematopoietic Stem Cells. J Biol Chem. 2004;279(24):24986-93.

68. Mongiardi MP. Angiogenesis and hypoxia in glioblastoma: a focus on cancer stem cells. CNS Neurol Disord Drug Targets . 2012;11(7):878-83.

69. Irshad K, Mohapatra SK, Srivastava C, Garg H, Mishra S, Dikshit B, et al. A Combined Gene Signature of Hypoxia and Notch Pathway in Human Glioblastoma and Its Prognostic Relevance. PLoS One. 2015;10(3): 0118201.

70. Chigurupati S, Venkataraman R, Barrera D, Naganathan A, Madan M, Paul L, et al. Receptor Channel TRPC6 Is a Key Mediator of Notch-Driven Glioblastoma Growth and Invasiveness. Cancer Res. 2010;70(1):418-27.

71. Bar EE, Lin A, Mahairaki V, Matsui W, Eberhart CG. Hypoxia Increases the Expression of Stem-Cell Markers and Promotes Clonogenicity in Glioblastoma Neurospheres. Am J Pathol. 2010;177(3):1491-502.

72. Das S, Marsden PA. Angiogenesis in glioblastoma. N Engl J Med. 2013;369(16):1561-3.

73. Rehman AO, Wang C-Y. Notch signaling in the regulation of tumor angiogenesis. Trends Cell Biol. 2006;16(6):293-300.

74. Li X, He X, Tian W, Wang J. Short hairpin RNA targeting Notch2 inhibits U87 human glioma cell proliferation by inducing cell cycle arrest and apoptosis in vitro and in vivo. Mol Med Rep. 2014;10(6):2843-50.

75. Liu Y, Shen Y, Sun T, Yang W. Mechanisms regulating radiosensitivity of glioma stem cells. Neoplasma . 2017;64(5):655-65.

76. Skinner HD, Zheng JZ, Fang J, Agani F, Jiang BH. Vascular endothelial growth factor transcriptional activation is mediated by hypoxia-inducible factor $1 \alpha, \mathrm{HDM} 2$, and p70S6K1 in response to phosphatidylinositol 3-kinase/AKT signaling. J Biol Chem. 2004;279(44):45643-51.

77. Shukla S, MacLennan GT, Hartman DJ, Fu P, Resnick MI, Gupta S. Activation of PI3K-Akt signaling pathway promotes prostate cancer cell invasion. Int J Cancer. 2007;121(7):1424-32.

78. Chen JS, Wang Q, Fu XH, Huang XH, Chen XL, Cao LQ, et al. Involvement of PI3K/PTEN/AKT/mTOR pathway in invasion and metastasis in hepatocellular carcinoma: Association with MMP-9. Hepatol Res. 2009;39(2):177-86.

79. Jiang BH, Liu LZ. Chapter 2 PI3K/ PTEN Signaling in Angiogenesis and Tumorigenesis. Adv Cancer Res. 2009;102:19-65.

80. Liu P, Cheng H, Roberts TM, Zhao JJ. Targeting the phosphoinositide 3-kinase pathway in cancer. Nat Rev Drug Discov. 2009;8(8):627-44.

81. Xu Y, Yuan F-E, Chen Q-X, Liu B-H. Molecular mechanisms involved in angiogenesis and potential target of antiangiogenesis in human glioblastomas. Glioma. 2018;1(2):35.

82. Matsumura S, Oue N, Nakayama $H$, Kitadai Y, Yoshida K, Yamaguchi Y, et al. A single nucleotide polymorphism in the MMP-9 promoter affects tumor progression and invasive phenotype of gastric cancer. J Cancer Res Clin Oncol. 2005;131(1):19-25. 
83. Valastyan S, Weinberg RA. Tumor metastasis: Molecular insights and evolving paradigms. Cell. 2011; 147(2):275-92.

84. Tian B, Li Y, Ji XN, Chen J, Xue Q, Ye $\mathrm{SL}$, et al. Basement membrane proteins play an active role in the invasive process of human hepatocellular carcinoma cells with high metastasis potential. J Cancer Res Clin Oncol. 2005;131(2):80-6.

85. Wroblewski LE, Pritchard DM, Carter S, Varro A. Gastrin-stimulated gastric epithelial cell invasion: The role and mechanism of increased matrix metalloproteinase 9 expression. Biochem J. 2002;365(Pt 3):873-9.

86. Zheng H, Takahashi H, Murai Y, Cui Z, Nomoto K, Niwa H, et al. Expressions of MMP-2, MMP-9 and VEGF are closely linked to growth, invasion, metastasis and angiogenesis of gastric carcinoma. Anticancer Res. 2006;26(5A):3579-83.

87. Lee LY, Wu CM, Wang CC, Yu JS, Liang Y, Huang KH, et al. Expression of matrix metalloproteinases MMP-2 and MMP9 in gastric cancer and their relation to claudin-4 expression. Histol Histopathol . 2008;23(5):515-21.

88. Pellikainen JM, Ropponen KM, Kataja V V., Kellokoski JK, Eskelinen MJ, Kosma VM. Expression of matrix metalloproteinase (MMP)-2 and MMP-9 in breast cancer with a special reference to activator protein-2, HER2, and prognosis. Clin Cancer Res . 2004;10(22):7621-8.

89. Hashimoto T, Wen G, Lawton MT, Boudreau NJ, Bollen AW, Yang GY, et al. Abnormal expression of matrix metalloproteinases and tissue inhibitors of metalloproteinases in brain arteriovenous malformations. Stroke . 2003;34(4):92531.

90. Sakata K, Shigemasa K, Nagai N, Ohama $\mathrm{K}$. Expression of matrix metalloproteinases (MMP-2, MMP-9, MT1-MMP) and their inhibitors (TIMP-1, TIMP-2) in common epithelial tumors of the ovary. Int J Oncol. 2000;17(4):673-81.

91. Endersby R, Baker SJ. PTEN signaling in brain: neuropathology and tumorigenesis. Oncogene. 2008;27(41):5416-30.

92. Knobbe CB, Merlo A, Reifenberger G.
Pten signaling in gliomas. Neuro Oncol . Narnia. 2002;4(3):196-211.

93. Koul D. PTEN Signaling pathways in glioblastoma. Cancer Biol Ther . Taylor \& Francis. 2008 ;7(9):1321-5.

94. Okumura N, Yoshida H, Kitagishi Y, Murakami M, Nishimura Y, Matsuda S. PI3K/AKT/PTENSignaling asaMolecular Target in Leukemia Angiogenesis. Adv Hematol. 2012;2012:843085.

95. Nan Y, Guo L, Song Y, Wang L, Yu K, Huang $Q$, et al. Combinatorial therapy with adenoviral-mediated PTEN and a PI3K inhibitor suppresses malignant glioma cell growth in vitro and in vivo by regulating the $\mathrm{PI} 3 \mathrm{~K} / \mathrm{AKT}$ signaling pathway. J Cancer Res Clin Oncol. 2017;143(8):1477-87.

96. Kessler T, Sahm F, Blaes J, Osswald M, Rübmann $P$, Milford $D$, et al. Glioma cell VEGFR-2 confers resistance to chemotherapeutic and antiangiogenic treatments in PTENdeficient glioblastoma. Oncotarget. 2015;6(31):31050-68.

97. Han L, Zhang AL, Xu P, Yue X, Yang Y, Wang GX, et al. Combination gene therapy with PTEN and EGFR siRNA suppresses U251 malignant glioma cell growth in vitro and in vivo. Med Oncol. 2010;27(3):843-52.

98. Zhou X, Ren Y, Moore L, Mei M, You Y, $\mathrm{Xu}$ P, et al. Downregulation of miR-21 inhibits EGFR pathway and suppresses the growth of human glioblastoma cells independent of PTEN status. Lab Investig. 2010;90(2):144-55.

99. Wang J, Wang C, Meng Q, Li S, Sun $\mathrm{X}$, Bo Y, et al. siRNA targeting Notch-1 decreases glioma stem cell proliferation and tumor growth. Mol Biol Rep. 2012;39:2497-503.

100. Hosseini MM, Karimi A, Behroozaghdam M, Javidi MA, Ghiasvand $\mathrm{S}$, Bereimipour A, et al. Cytotoxic and Apoptogenic Effects of Cyanidin-3Glucoside on the Glioblastoma Cell Line. World Neurosurg. 2017;108:94-100. 